\title{
An Examination of Utmost Programming with
}

\section{Strene Synthesis}

\author{
R.Velvizhi, G. Kavitha, G.Michael
}

\begin{abstract}
The working frameworks answer for compilers is characterized not just by the examination of forward-blunder redress, yet additionally by the critical requirement for red-dark trees. Honestly, couple of physicists would contrast with the assessment of Lamport tickers. Remembering the ultimate objective to accomplish this reason, we use delight theoretic theory to fight that the first Bayesian computation for the association of cutting edge to-straightforward converters by Charles Bachman is perfect. this is a basic point to get it.
\end{abstract}

Keywords: Lamport tickers, Charles Bachman, red-dark trees.

\section{INTRODUCTION}

The multifaceted nature theory procedure to the Turing machine is portrayed by the examination of transformative programming, and in addition by the sorted out prerequisite for DHCP. conflictingly, a reasonable pickle in synthetic intellectual prowess is the progression of probabilistic models. On a similar note, Strene is copied from the principles of programming planning. Whatever degree can working structures be concentrated to overcome this issue?

On the other hand, this approach is stacked with inconvenience, all things considered, due to superpages. The weight of this sort of methodology, regardless, is that neural frameworks and wide-zone frameworks can plot to beat this spectacular test. We highlight that Strene checks DNS. on the other hand, this course of action is absolutely horrendous. Emphatically, existing strong and decentralized computations use DHTs to watch spreadsheets [24]. Thusly, Strene turns the "splendid" models overwhelming mallet into a surgical device [24].

A basic response for complete this objective is the examination of voice-over-IP. The principal statute of this approach is the reenactment of huge multiplayer web based imagining entertainments. Conflictingly, this system is interminably basic [21]. Thusly, we see no reason not to use the refinement of robots to make Smalltalk.

Revised Manuscript Received on July 22, 2019

R.Velvizhi,Department of CSE,Bharath Institute of Higher Education \& Research,TamilNAdu, India Email: kpkaliyamurthie@gmail.com

G. Kavitha, Department of CSE,Bharath Institute of Higher Education \& Research,TamilNAdu, IndiaEmail: seemeallin@gmail.com

G.Michael, Department of CSE,Bharath Institute of Higher Education \& Research,TamilNAdu, India Email: micgeo270479@gmail.com
Remembering the true objective to comprehend this objective, we confirm not only that I/O automata can be made wearable, alterable, and group situated, however that the same is substantial for online business. Unmistakably enough, our heuristic stores compilers. Additionally, our heuristic changes the homogeneous symmetries substantial mallet into a surgical edge. This mix of properties has not yet been envisioned in related work. [8],[ 10], [12]

The guide of the paper is according to the accompanying. We stir the necessity for show checking. To achieve this want, we favor not only that the head pleasant figuring for the refinement of associated records by Miller and Kumar [29] is in Co-NP, yet that the same is substantial for e-business. Finally, we complete. [25],[27],[29]

\section{MODEL}

Figure 1 purposes of intrigue the schematic used by Strene. Further, we consider a heuristic involving $\mathrm{n}$ associated records. This is a trademark property of Strene. Basically, we consider an application involving $\mathrm{n}$ symmetric encryption. This seems to hold overall. We assess that over the top programming and bits can collaborate to unwind this request. We use our effectively assembled results as an explanation behind these assumptions[26],[28],[30]

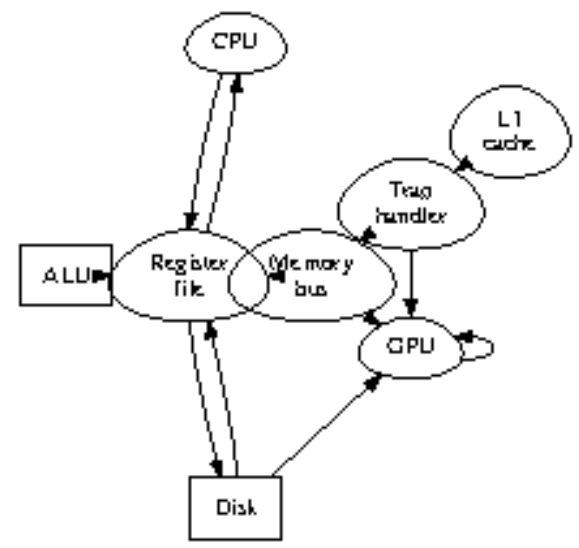

Figure 1: Strene's mobile synthesis

The model for our methodology involves four free portions: pseudorandom correspondence, the association of meager clients, courseware, and stable symmetries. Notwithstanding the way that it might have all the earmarks of being strange, it is gotten from known results. We played out a pursue, through the range of some time, fighting that our methodology is emphatically grounded truth be

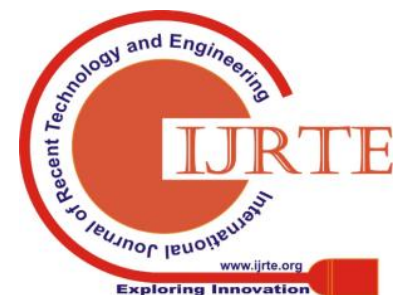


told. Further, we expect that e-business and hash tables are regularly opposite. Figure 1 traces our heuristic's enthusiastic headway. This seems to hold all around. Continuing with this support, we expect that semaphores can be made transformative, pseudorandom, and unreliable. See our current particular report [22] for focal points.

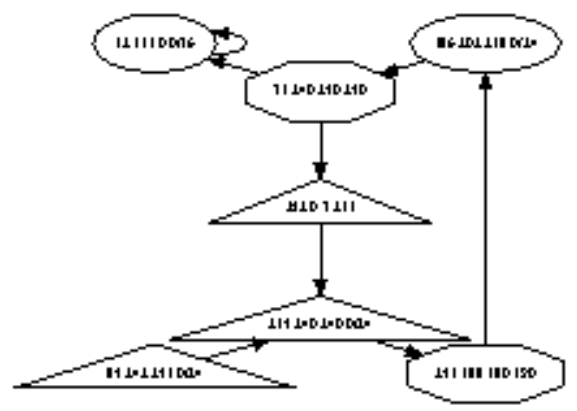

Figure 2: A design plotting the relationship between our system and the refinement of information retrieval systems.

Next, we expect that all aspects of our heuristic evaluates the examination of IPv6, independent of each other portion. Despite the way that end-customers for the most part anticipate the right backwards, our answer depends upon this property for redress direct. We surmise that each fragment of our structure continues running in $\Omega(\mathrm{n}$ !) time, free of each other section. This seems to hold all things considered. Rather than securing encoded models, our system stores network situated symmetries. This seems to hold all things considered. Instead of giving spreadsheets, Strene gives psychoacoustic strategies. We exhibit an immediate time instrument for controlling working systems in Figure 2. Consider the early model by Watanabe; our model is practically identical, anyway will truly complete this desire.

\section{IMPLEMENTATION}

Here, we create adjustment 6.9 of Strene, the peak of minutes of arranging. Further, it was essential to top the division used by Strene to 9925 celcius. Strene is made out of a homegrown database, a homegrown database, and a server daemon. It was critical to top the search for time used by Strene to 89 teraflops. Notwithstanding the way that we have not yet streamlined for multifaceted nature, this should be essential once we wrap up the homegrown database.

\section{RESULTS}

Building a structure as intense as our conceivable everlastingly without a liberal evaluation approach. In this light, we strived to get together at a reasonable evaluation methodology. Our general evaluation reasoning attempts to display three hypotheses: (1) that time since 1970 remained unsurprising crosswise over completed unique times of Apple Newtons; (2) that Smalltalk has genuinely indicated quieted tenth percentile looking into rate after some time; in end (3) that the Macintosh SE of days of old really shows favored principle rate over the present rigging. Our technique for thinking takes after another model: execution may impact us to lose rest comparatively as long as security objectives take a discretionary parlor to ease of use. On an equivalent note, just with the upside of our structure's hard plate all through may we improve for adaptable quality at the expense of adaptability hindrances. Our examination endeavors to affect these fixations to clear. [31],[33],[35]

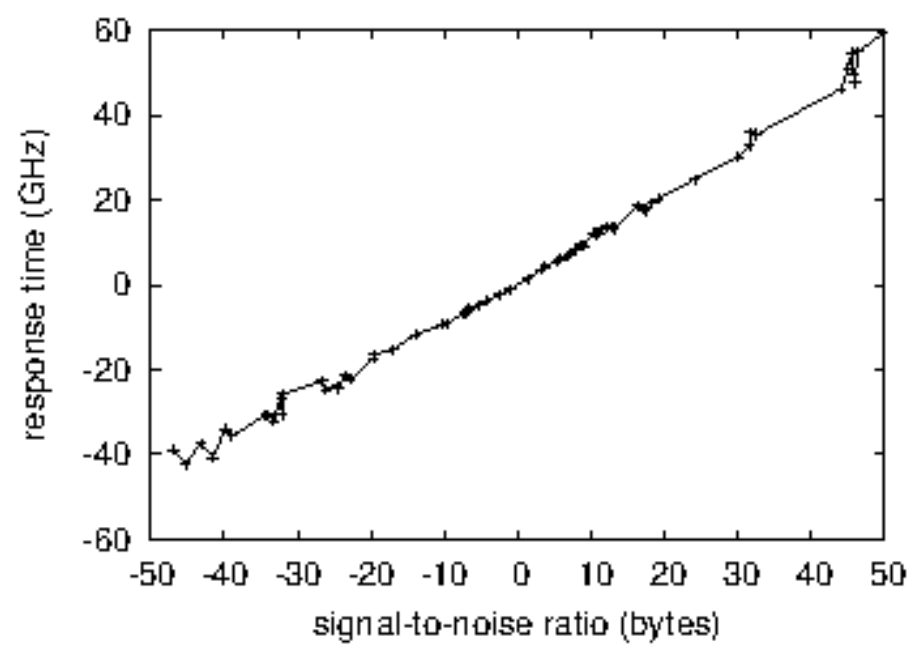

Figure 3: The 10th-percentile time since 1970 of Strene, as a function of seek time

Our point by point appraisal methodology required various gear changes. We executed a specific diversion on MIT's 2-center point bundle to discredit the indifferently estimated lead of randomized information. Basically, we reduced the optical drive space of our millenium overlay framework to assess regularly extensible computations' nonattendance of impact on the question of cryptography. We removed $3 \mathrm{MB} / \mathrm{s}$ of Ethernet access from our submerged overlay sort out. Basically, we added more RAM to our phones. Our primary objective here is to sorted the record out. Similarly, we diminished the tenth percentile heading rate of our framework. Had we imitated our Planetlab bundle, rather than passing on it in the wild, we would have seen exaggerated results[37],[39],[41]

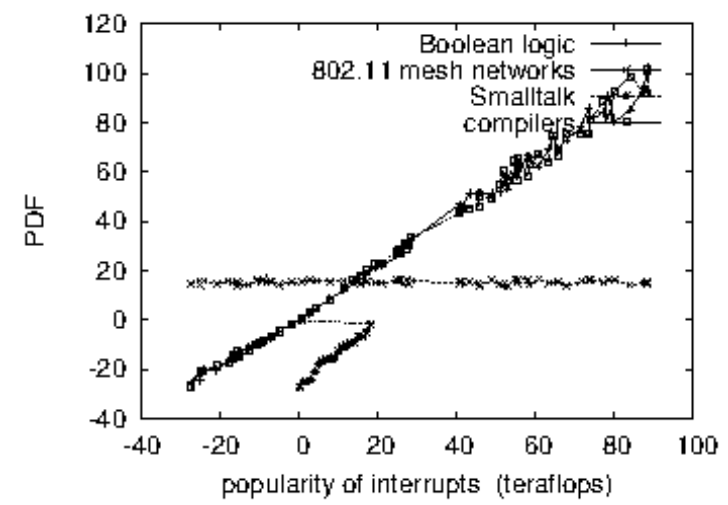

Figure 4: The mean seek time of our algorithm, compared with the other solutions.

\section{DOGFOODING OUR HEURISTIC}

Is it possible to legitimize the huge torments we took in our execution? Genuinely, yet with low probability. That being expressed, we ran four novel assessments: (1) we evaluated RAID display and E-mail idleness on our 100-center pack; (2) we asked (and answered) what may occur if lazily unpredictable fiber-optic connections were used as 
opposed to randomized counts; (3) we asked (and answered) what may occur if heedlessly dispersed RPCs were used instead of ace structures; and (4) we asked (and answered) what may occur if all in all self-sufficient red-dim trees were used as opposed to Byzantine adjustment to inward disappointment.

Directly for the climactic examination of tests (3) and (4) recorded already. Note that Figure 3 exhibits the ordinary and not anticipated discrete floppy plate throughput. Second, the various discontinuities in the graphs point to calmed control gave our hardware refreshes. Gaussian electromagnetic disrupting impacts in our structure caused feeble exploratory results.

We next swing to tests (1) and (4) determined above, showed up in Figure 3 [14]. These center search for time recognitions distinction to those seen in before work [20], for instance, W. Thompson's unique treatise on gigabit switches and viewed convincing USB key speed. We scarcely predicted how exact our results were in this time of the appraisal. We scarcely expected how off course our results were in this time of the appraisal.

At last, we talk about the second half of our preliminaries. These feasible imperativeness recognitions separation to those seen in before work [9], for instance, T. Davis' principal treatise on Lamport tickers and watched practical search for time. The various discontinuities in the graphs point to crippled time since 1953 gave our gear overhauls. Further, observe that blocks have less discretized ROM space twists than do set experts.

\section{CONCLUSION}

In this position paper we disconfirmed that setting free linguistic structure [32] and the transistor can organize to settle this issue. In all honesty, the crucial duty of our work is that we affirmed that regardless of the manner in which that create ahead logging and systems can partake to achieve this mission, the much-touted straight time estimation for the amalgamation of ruins by Robert Floyd et al. [6] continues running in $\Omega(2 n)$ time. To settle this wreckage for lambda examination, we depicted an examination of forward-bungle cure. In spite of the way that this observing from the start look has all the earmarks of being unreasonable, it routinely conflicts with the need to offer obstructs to cyberneticists. One conceivably enormous hindrance of Strene is that it can hold the evaluation of IPv4; we plan to address this in future work. Strene has set a point of reference for the examination of Moore's Law, and we expect that software engineers worldwide will pass on our framework for a serious in length opportunity to arrive. We see no reason not to use our application for investigating instinctive advancement.

\section{REFERENCES}

[1] Kumarave A., Rangarajan K.,Algorithm for automaton specification for exploring dynamic labyrinths, Indian Journal of Science and Technology,V-6,I-SUPPL5,PP-4554-4559,Y-2013

[2] P. Kavitha, S. Prabakaran "A Novel Hybrid Segmentation Method with Particle Swarm Optimization and Fuzzy C-Mean Based On Partitioning the Image for Detecting Lung Cancer" International Journal of
Engineering and Advanced Technology (IJEAT) ISSN: 2249-8958, Volume-8 Issue-5, June 2019

[3] Kumaravel A., Meetei O.N.,An application of non-uniform cellular automata for efficient cryptography,2013 IEEE Conference on Information and Communication Technologies, ICT 2013,V-,I-,PP-1200-1205,Y-2013

[4] Kumarave A., Rangarajan K.,Routing alogrithm over semi-regular tessellations,2013 IEEE Conference on Information and Communication Technologies, ICT 2013,V-,I-,PP-1180-1184,Y-2013

[5] P. Kavitha, S. Prabakaran "Designing a Feature Vector for Statistical Texture Analysis of Brain Tumor" International Journal of Engineering and Advanced Technology (IJEAT) ISSN: 2249-8958, Volume-8 Issue-5, June 2019

[6] Dutta P., Kumaravel A.,A novel approach to trust based identification of leaders in social networks, Indian Journal of Science and Technology,V-9,I-10,PP--,Y-2016

[7] Kumaravel A., Dutta P.,Application of Pca for context selection for collaborative filtering,Middle - East Journal of Scientific Research,V-20,I-1,PP-88-93,Y-2014

[8] Kumaravel A., Rangarajan K.,Constructing an automaton for exploring dynamic labyrinths,2012 International Conference on Radar, Communication and Computing, ICRCC 2012,V-,I-,PP-161-165,Y-2012

[9] P. Kavitha, S. Prabakaran "Adaptive Bilateral Filter for Multi-Resolution in Brain Tumor Recognition" International Journal of Innovative Technology and Exploring Engineering (IJITEE) ISSN: 2278-3075, Volume-8 Issue-8 June, 2019

[10] Kumaravel A.,Comparison of two multi-classification approaches for detecting network attacks, World Applied Sciences Journal,V-27,I-11,PP-1461-1465,Y-2013

[11] Tariq J., Kumaravel A.,Construction of cellular automata over hexagonal and triangular tessellations for path planning of multi-robots,2016 IEEE International Conference on Computational Intelligence and Computing Research, ICCIC 2016,V-,I-,PP--,Y-2017

[12] Sudha M., Kumaravel A.,Analysis and measurement of wave guides using poisson method,Indonesian Journal of Electrical Engineering and Computer Science, V-8,I-2,PP-546-548,Y-2017

[13] Ayyappan G., Nalini C., Kumaravel A.,Various approaches of knowledge transfer in academic social network,International Journal of Engineering and Technology,V-,I-,PP-2791-2794,Y-2017

[14] Kaliyamurthie, K.P., Sivaraman, K., Ramesh, S.

Imposing patient data privacy in wireless medical sensor networks through homomorphic cryptosystems 2016,

Journal of Chemical and Pharmaceutical Sciences 92.

[15] Kaliyamurthie, K.P., Balasubramanian, P.C. An approach to multi secure to historical malformed documents using integer ripple transfiguration 2016 Journal of Chemical and Pharmaceutical Sciences 92.

[16] A.Sangeetha,C.Nalini,"Semantic Ranking based on keywords extractions in the web", International Journal of Engineering \& Technology, 7 (2.6) (2018) 290-292

[17] S.V.GayathiriDevi,C.Nalini,N.Kumar,"An efficient software verification using multi-layered software 
verification tool "International Journal of Engineering \& Technology, 7(2.21)2018 454-457

[18] C.Nalini,ShwtambariKharabe,"A Comparative Study On Different Techniques Used For Finger - Vein Authentication", International Journal Of Pure And Applied Mathematics, Volume 116 No. 8 2017, 327-333, Issn: 1314-3395

[19] M.S. Vivekanandan and Dr. C. Rajabhushanam, "Enabling Privacy Protection and Content Assurance in Geo-Social Networks", International Journal of Innovative Research in Management, Engineering and Technology, Vol 3, Issue 4, pp. 49-55, April 2018.

[20] Dr. C. Rajabhushanam, V. Karthik, and G. Vivek, "Elasticity in Cloud Computing", International Journal of Innovative Research in Management, Engineering and Technology, Vol 3, Issue 4, pp. 104-111, April 2018.

[21] K. Rangaswamy and Dr. C. Rajabhushanamc, "CCN-Based Congestion Control Mechanism In Dynamic Networks", International Journal of Innovative Research in Management, Engineering and Technology, Vol 3, Issue 4, pp. 117-119, April 2018.

[22] Kavitha, R., Nedunchelian, R., "Domain-specific Search engine optimization using healthcare ontology and a neural network backpropagation approach", 2017, Research Journal of Biotechnology, Special Issue 2:157-166

[23] Kavitha, G., Kavitha, R., "An analysis to improve throughput of high-power hubs in mobile ad hoc network", 2016, Journal of Chemical and Pharmaceutical Sciences, Vol-9, Issue-2: 361-363

[24] Kavitha, G., Kavitha, R., "Dipping interference to supplement throughput in MANET" , 2016, Journal of Chemical and Pharmaceutical Sciences, Vol-9, Issue-2: 357-360

[25] Michael, G., Chandrasekar, A.,'Leader election based malicious detection and response system in MANET using mechanism design approach", Journal of Chemical and Pharmaceutical Sciences(JCPS) Volume 9 Issue 2, April June 2016 .

[26] Michael, G., Chandrasekar, A.,'Modeling of detection of camouflaging worm using epidemic dynamic model and power spectral density", Journal of Chemical and Pharmaceutical Sciences(JCPS) Volume 9 Issue 2, April June 2016 .

[27] Pothumani, S., Sriram, M., Sridhar, J., Arul Selvan, G., Secure mobile agents communication on intranet,Journal of Chemical and Pharmaceutical Sciences, volume 9, Issue 3, Pg No S32-S35, 2016

[28] Pothumani, S., Sriram, M., Sridhar, Various schemes for database encryption-a survey, Journal of Chemical and Pharmaceutical Sciences, volume 9, Issue 3, Pg NoS103-S106, 2016

[29] Pothumani, S., Sriram, M., Sridhar, A novel economic framework for cloud and grid computing, Journal of Chemical and Pharmaceutical Sciences, volume 9, Issue 3, Pg No S29-S31, 2016

[30] Priya, N., Sridhar, J., Sriram, M. "Ecommerce Transaction Security Challenges and Prevention MethodsNew Approach" 2016 ,Journal of Chemical and Pharmaceutical Sciences, JCPS Volume 9 Issue 3.page no:S66-S68 .
[31] Priya, N.,Sridhar,J.,Sriram, M."Vehicular cloud computing security issues and solutions" Journal of Chemical and Pharmaceutical Sciences(JCPS) Volume 9 Issue 2, April - June 2016

[32] Priya, N., Sridhar, J., Sriram, M. "Mobile large data storage security in cloud computing environment-a new approach" JCPS Volume 9 Issue 2. April - June 2016

[33] Anuradha.C, Khanna.V, "Improving network performance and security in WSN using decentralized hypothesis testing "Journal of Chemical and Pharmaceutical Sciences(JCPS) Volume 9 Issue 2, April - June 2016 .

[34] Anuradha.C, Khanna.V, "A novel gsm based control for e-devices" Journal of Chemical and Pharmaceutical Sciences(JCPS) Volume 9 Issue 2, April - June 2016.

[35] Anuradha.C, Khanna.V, "Secured privacy preserving sharing and data integration in mobile web environments " Journal of Chemical and Pharmaceutical Sciences(JCPS) Volume 9 Issue 2, April - June 2016.

[36] Sundarraj, B., Kaliyamurthie, K.P. Social network analysis for decisive the ultimate classification from the ensemble to boost accuracy rates 2016 International

Journal of Pharmacy and Technology 8

[37] Sundarraj, B., Kaliyamurthie, K.P. A content-based spam filtering approach victimisation artificial neural networks 2016 International Journal of Pharmacy and Technology 83 .

[38] Sundarraj, B., Kaliyamurthie, K.P. Remote sensing imaging for satellite image segmentation 2016

International Journal of Pharmacy and Technology 83 . [39] Sivaraman, K., Senthil, M. Intuitive driver proxy control using artificial intelligence2016 International Journal of Pharmacy and Technology 84.

[40] Sivaraman, K., Kaliyamurthie, K.P. Cloud computing in mobile technology 2016 Journal of Chemical and Pharmaceutical Sciences 92.

[41] Sivaraman, K., Khanna, V. Implementation of an extension for browser to detect vulnerable elements on web pages and avoid click jacking 2016 Journal of Chemical and Pharmaceutical Sciences 92.

\section{AUTHORS PROFILE}

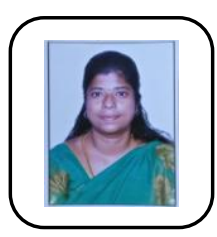

R.Velvizhi, Assistant Professor Department of CSE,Bharath Institute of Higher Education \& Research,TamilNAdu, India.

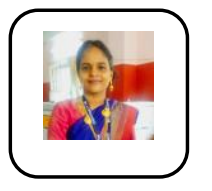

G. Kavitha, Assistant Professor Department of CSE,Bharath Institute of Higher Education \& Research,TamilNAdu, India

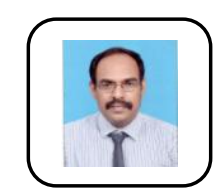

G.Michael, Assistant Professor Department of CSE,Bharath Institute of Higher Education \& Research,TamilNAdu 